\title{
PENGARUH STRATEGI PEMECAHAN MASALAH WANKAT-OREOVOCZ DAN PEMBELAJARAN TEKNIK PROBING TERHADAP KEMAMPUAN LITERASI MATEMATIS SISWA SMP
}

\author{
Nego Linuhung \\ FKIP Universitas Muhammadiyah Metro \\ E-mail: nego_mtk@yahoo.co.id
}

\begin{abstract}
Low of mathematical literacy become this research base. Alternative solution in overcoming the problem is needed absolutely, so this research aim to analyze the essence of learning the strategy of Wankat-Oreovocz problem solving and the Probing Technique learning as alternative the problem solution. The research design which is used is a non-equivalent control group design by using technique of Purposive Sampling. The Research Subject is all eight grade students of Sukahaji Junior High School with the research sample is eight grade students. The research instrument used in the form is mathematical literacy test of level 5, teaching materials and questionnaire. Result of the research indicates that: There is not the difference of mathematical literacy of level 5 at student who is getting strategy of Wankat-Oreovocz problem solving (WO) and the Probing Technique learning (TP).
\end{abstract}

Keywords: Mathematical Literacy Level 5, The Strategy of Wankat-Oreovocz Problem Solving, and Probing Technique Learning

PENDAHULUAN

Pendidikan tidak akan terlepas dari proses pembelajaran yang terjadi di lingkungan sekolah. Proses pembelajaran yang terjadi dalam lingkungan tersebut dapat mengubah peserta didik yang menyangkut perubahan peningkatan pengetahuan (kognitif), nilai dan sifat (afektif) dan perubahan peningkatan keterampilan (psikomotorik). Hal inilah tanda-tanda proses pembelajaran itu berhasil.
Permendiknas Nomor 22 Tahun 2006 tentang Standar Isi Mata Pelajaran Matematika lingkup pendidikan dasar menyebutkan bahwa mata pelajaran matematika bertujuan agar peserta didik memiliki kemampuan kemampuan pemahaman matematis, penalaran matematis, pemecahan masalah matematis, komunikasi matematis, serta sikap menghargai kegunaan matematika. selanjutnya Organisation for Economic Cooperation and Development (OECD) (2010) mendefinisikan bahwa literasi matematis adalah kemampuan 
seseorang untuk merumuskan, matematika dalam berbagai konteks, termasuk kemampuan melakukan penalaran secara matematis dan menggunakan konsep, prosedur, dan fakta untuk menggambarkan, menjelaskan atau memperkirakan fenomena/kejadian. Membandingkan antara pengertian literasi matematis dengan tujuan mata pelajaran matematika pada Standar Isi tersebut, tampak ada kesesuaian atau kesepahaman, sehingga jelas bahwa kemampuan dalam tujuan mata pelajaran matematika menurut Standar Isi mata pelajaran matematika pada intinya adalah juga kemampuan yang dikenal sebagai literasi matematis.

Salah satu indikator yang menunjukkan rendahnya literasi matematis siswa Indonesia adalah hasil survei yang dilakukan oleh Programme for International Student Assessment (PISA) yang mengukur kemampuan anak usia 15 tahun dalam literasi membaca, matematika, dan ilmu pengetahuan. Terakhir pada tahun 2009 skor rata-rata Indonesia 371 menempatkan peringkat Indonesia pada posisi 61 dari 65 negara (Balitbang, 2011). Indonesia selalu masuk pada peringkat jajaran terbawah klasemen dan juga skor yang diperoleh selalu di bawah rata-rata, jelas ini bukan hasil yang diharapkan. Literasi matematis siswa dalam PISA terbagi menjadi 6 tingkatan atau level. Literasi level 1 dan level 2 merupakan kelompok soal dengan skala paling bawah. Soal literasi level 3 dan level 4 termasuk dalam kelompok soal dengan sekala menengah, sedangkan soal literasi level 5 dan level 6 merupakan kelompok soal dengan skala tinggi. Menurut studi PISA siswasiswa Indonesia menempati pada level 1 dan level 2 yaitu tingkatan yang masih mengacu pada soal-soal rutin.

Hasil PISA yang rendah tersebut tentunya disebabkan oleh banyak faktor. Salah satu faktor penyebab antara lain siswa Indonesia pada umumnya kurang terlatih dalam menyelesaikan soal-soal dengan karakteristik seperti soal-soal pada PISA. Hal itu setidaknya dapat dicermati dari contoh-contoh instrumen penilaian hasil belajar yang didesain oleh para guru matematika Sekolah Menengah Pertama (SMP) di Indonesia dalam model pengembangan silabus yang diterbitkan oleh Badan Standar Nasional Pendidikan (BSNP) pada tahun 2007. Menyikapi permasalahan di atas, suatu alternatif pembelajaran dilakukan untuk meningkatkan literasi matematis yaitu dengan menerapkan pembelajaran yang banyak melatih siswa untuk mencapai kemampuan tertinggi pada bidang matematika.

Menyikapi permasalahan rendahnya literasi matematis siswa Indonesia, suatu alternatif pembelajaran dilakukan untuk meningkatkan literasi matematis yaitu dengan menerapkan pembelajaran yang banyak melatih 
siswa untuk mencapai kemampuan tertinggi pada bidang matematika. Penelitian ini diharapkan dapat meningkatkan literasi matematis siswa Indonesia pada level 5 .

Adapun alasan peneliti ingin meningkatkan literasi matematis pada level 5 yaitu: (1) Menurut studi PISA siswa-siswa Indonesia menempati pada level 1 dan level 2; (2) Pada literasi matematis level 3 dan level 4 kemampuan yang diukur sudah tercakup pada level 5; (3) Literasi yang diukur menurut studi PISA pada level 5 (dalam Maryanti, 2012) adalah kemampuan siswa untuk dapat bekerja dengan model untuk situasi yang kompleks, mengidentifikasi kendala yang dihadapi dan melakukan dugaandugaan. Mereka dapat memilih, membandingkan, dan mengevaluasi sesuai dengan strategi pemecahan masalah dalam menghadapi masalahmasalah kompleks yang berhubungan dengan model tersebut. Berdasarkan kemampuan yang diukur pada level 5 tersebut dapat disimpulkan bahwa literasi matematis siswa pada level 5 sesuai dengan tujuan mata pelajaran matematika yang dicanangkan oleh Permendiknas.

Kegiatan pembelajaran di sekolah harus mengarahkan siswa untuk menerapkan matematika pada persoalan yang berakar dari permasalahan seharihari yang sering disebut literasi matematis dan mengarahkan siswa agar terlatih dalam pengerjaan untuk menyelesaikan masalah tersebut. Akibat dari permasalahan ini guru hendaknya dapat menggunakan strategi yang tepat yang dapat membantu siswa meningkatkan literasi matematis untuk menyelesaikan persoalan-persoalan kehidupan sehari-hari. Pembelajaran yang diduga dapat meningkatkan literasi matematis siswa level 5 yaitu pembelajaran strategi pemecahan masalah Wankat-Oreovocz. Menurut Wena (2009), strategi pemecahan masalah Wankat-Oreovocz memiliki tujuh langkah pemecahan masalahnya, tahapan tersebut dimulai dari saya mampu/bisa, mendefinisikan, mengeksplorasi, merencanakan, mengerjakan, mengoreksi kembali dan terakhir adalah generalisasi. Adapun yang merupakan ciri khas dari strategi Wankat-Oreovocz adalah pemberian motivasi karena kunci dari sebuah keberhasilan adalah motivasi besar yang tumbuh dalam diri siswa dan langkah awal siswa dalam strategi Wankat-Oreovocz adalah guru membuat siswa merasa bahwa mereka bisa menguasai apa yang mereka akan pelajari hal ini sangat berpengaruh pada semangat mereka untuk menyelesaikan masalah yang berkaitan dengan literasi matematis.

Pembelajaran lain yang diduga dapat meningkatkan literasi matematis adalah pembelajaran dengan Teknik Probing. Pada pembelajarannya guru memberikan serangkaian pertanyaan kepada siswa yang sifatnya 
membimbing dan menggali, sehingga terjadi proses berpikir yang mengaitkan pengetahuan setiap siswa dan pengalamannya dengan pengetahuan baru yang disajikan guru. Teknik Probing diawali dengan menghadapkan siswa pada situasi baru yang mengandung teka-teki atau bendabenda nyata. Situasi baru itu membuat siswa mengalami pertentangan dengan pengetahuan yang sudah dimilikinya sehingga memberikan peluang kepada siswa untuk mengadakan asimilasi, disinilah Probing (pembimbingan menggunakan satu seri pertanyaan) mulai diperlukan. Berdasarkan langkahlangkah dan tujuannya, pembelajaran dengan Teknik Probing diduga dapat meningkatkan literasi matematis sebab pada pembelajarannya siswa dituntut untuk dapat menyelesaikan masalah baru, sehingga siswa terlatih dengan soal-soal literasi matematis. Berdasarkan karakteristik dan tujuan dari pembelajaran dengan strategi pemecahan masalah Wankat-Oreovocz dan pembelajaran dengan Teknik Probing, kedua pembelajaran tersebut sangat mendukung untuk dapat meningkatkan literasi matematis level 5.

Berdasarkan latar belakang masalah yang telah diuraikan, penelitian ini bertujuan untuk mengetahui perbedaan kemampuan literasi matematis level 5 pada siswa yang mendapat pembelajaran strategi pemecahan masalah Wankat-Oreovocz dan siswa yang mendapat pembelajaran Teknik Probing.

\section{METODE PENELITIAN}

Dalam penelitian ini terdapat variabel bebas, yaitu pembelajaran dengan menggunakan strategi pemecahan masalah Wankat-Oreovocz dan pembelajaran dengan teknik Probing untuk melihat pengaruhnya terhadap variabel terikatnya, yaitu literasi matematis pada siswa. Penelitian ini merupakan penelitian kuasi eksperimen dengan desain kelompok kontrol non-ekivalen (Ruseffendi, 2005: 52). Penelitian ini adalah penelitian kuasi eksperimen yang dilaksanakan di SMP Negeri 1 Sukahaji. Subyek dalam penelitian ini meliputi seluruh siswa kelas VIII SMP N 1 Sukahaji semester 1 tahun pelajaran 2012/2013. Sampel penelitiannya adalah dua kelas VIII dari tujuh kelas paralel yang ada. Jumlah siswa pada kelas VIIIG sebagai kelas eksperimen 1 (EKS1) yang mendapat pembelajaran pembelajaran Pemecahan Masalah Wankat-Oreovocz (WO) sebanyak 31 siswa dan pada kelas VIIIB sebagai kelas eksperimen 2 (EKS2) yang mendapat pembelajaran dengan Teknik Probing (TP) sebanyak 32 siswa, sehingga jumlah siswa pada kedua kelas sampel adalah 63 siswa.

\section{HASIL DAN PEMBAHASAN}


Data kuantitatif diperoleh melalui tes literasi matematis level 5 di awal dan akhir pembelajaran. Data tersebut didapat dari 63 orang siswa, terdiri dari 31 siswa kelas EKS1 yang mendapat pembelajaran dengan strategi pemecahan masalah Wankat-Orevocz dan 32 siswa kelas EKS2 yang mendapat pembelajaran dengan TP. Berikut ini adalah uraian hasil penelitian.

Tabel 1. Statistik Deskriptif Skor Literasi Matematis Level 5 Siswa

\begin{tabular}{|l|c|c|c|c|c|}
\hline \multirow{2}{*}{ Kelas } & \multirow{2}{*}{$\begin{array}{c}\text { Jumlah } \\
\text { Siswa }\end{array}$} & \multicolumn{2}{|c|}{ Pretest } & \multicolumn{2}{c|}{ Posttest } \\
\cline { 3 - 6 } & & SD & & SD \\
\hline $\begin{array}{c}\text { EKS1 } \\
\text { (WO) }\end{array}$ & 31 & 25,61 & 12,3 & 49,71 & 11,01 \\
\hline $\begin{array}{c}\text { EKS2 } \\
\text { (TP) }\end{array}$ & 32 & 26,03 & 12,06 & 48,5 & 12,13 \\
\hline \multicolumn{6}{|c|}{ Skor maksimun ideal = 82 } \\
\hline
\end{tabular}

Berdasarkan Tabel 1. di atas diperoleh: (1) rataan pretest kelas EKS1 dan kelas EKS2, yaitu masing-masing sebesar 25,61 dan 26,03; sedangkan (2) rataan posttest kelas EKS1 dan kelas EKS2 yaitu masing-masing sebesar 49,71 dan 48,5.

Uji kesamaan pretest bertujuan untuk memperlihatkan apakah kemampuan awal kedua kelas sama atau berbeda signifikan. Sebelum data dianalisis terlebih dahulu dilakukan uji prasyarat analisis yaitu uji normalitas dan uji homogenitas.

Berdasarkan uji statistik diperoleh kesimpulan bahwa data skor pretest memenuhi uji prasyarat kenormalan dan homogenitas. Selanjutnya, dilakukan uji kesamaan rataan pretest dengan menggunakan Independent Sample t-test dengan bantuan program SPSS 16. Berikut hasil perhitungan selengkapnya:

Tabel 2. Uji Kesamaan Rataan Skor

Pretest

\begin{tabular}{|r|r|r|c|c|}
\hline \multicolumn{2}{|c|}{$\begin{array}{c}\text { t-test for Equality of } \\
\text { Means }\end{array}$} & \multirow{2}{*}{ Ket } & \multirow{2}{*}{$\begin{array}{c}\text { Kesim- } \\
\text { pulan }\end{array}$} \\
\cline { 1 - 2 } $\boldsymbol{t}$ & $\boldsymbol{d} \boldsymbol{f}$ & $\begin{array}{c}\text { Sig. (2- } \\
\text { tailed) }\end{array}$ & & \\
\hline 0,41 & 61 & 0,68 & $\begin{array}{c}\text { Ho } \\
\text { Diterima }\end{array}$ & $\begin{array}{c}\text { Tidak } \\
\text { Terdapat } \\
\text { Perbedaan }\end{array}$ \\
\hline
\end{tabular}

Dari Tabel 2. diperoleh hasil Independent Sample t-test, didapat nilai $p$-value atau Sig.(2-tailed) yaitu $0,68>\alpha=0,05$. Hal ini menunjukkan bahwa $\mathrm{H}_{0}$ diterima, artinya tidak terdapat perbedaan yang signifikan antara skor pretest literasi matematis level 5 siswa kelas EKS1 dan kelas EKS2. Dengan demikian kemampuan awal kedua kelas sama.

Untuk membuktikan bahwa apakah terdapat perbedaan kemampuan literasi matematis level 5 siswa pada siswa yang mendapat pembelajaran strategi pemecahan masalah WankatOreovocz dan siswa yang mendapat pembelajaran Teknik Probing, maka harus dilakukan uji kenormalan dan uji homogenitas. Setelah diketahui bahwa data skor posttest memenuhi uji prasyarat kenormalan dan homogenitas, sehingga bisa dilanjutkan pada uji 
kesamaan rataan posttest dengan menggunakan Independent Sample ttest dengan bantuan program SPSS 16.

Tabel 3. Uji Perbedaan Rataan Skor Posttest Literasi Matematis Level 5

\begin{tabular}{|c|c|c|c|c|}
\hline \multicolumn{2}{|c|}{$\begin{array}{c}\text { t-test for Equality of } \\
\text { Means }\end{array}$} & \multirow{2}{*}{ Ket } & $\begin{array}{c}\text { Kesim- } \\
\text { pulan }\end{array}$ \\
\cline { 1 - 2 } $\boldsymbol{t}$ & $\boldsymbol{d f}$ & $\begin{array}{c}\text { Sig. (2- } \\
\text { tailed) }\end{array}$ & & \\
\hline 0,52 & 61 & 0,605 & $\begin{array}{c}\text { Ho } \\
\text { Diterima }\end{array}$ & $\begin{array}{c}\text { Tidak } \\
\text { Terdapat } \\
\text { Perbedaan }\end{array}$ \\
\hline
\end{tabular}

Dari Tabel 3. diperoleh nilai $p$ value atau Sig.(2-tailed) yaitu $0,605>\alpha$ $=0,05$. Hal ini menunjukkan bahwa $\mathrm{H}_{0}$ diterima, artinya tidak terdapat perbedaan skor Posttest literasi matematis level 5 siswa yang mendapat pembelajaran dengan WO dengan siswa yang mendapat pembelajaran dengan TP. Dengan demikian kemampuan literasi matematis level 5 siswa kedua kelas sama.

Berdasarkan hasil penelitian yang sudah diuraikan di atas, pembelajaran dengan strategi pemecahan masalah Wankat-Oreovocz (WO) dan pembelajaran dengan teknik Probing (TP) dapat meningkatkan literasi matematis level 5 siswa. untuk mengetahui perbedaan kemampuan antara keduanya tersebut menggunakan uji independent sample t-test dengan bantuan program SPSS 16, berdasarkan hasil uji statistik yang telah dilakukan diperoleh fakta bahwa kemampuan literasi matematis level 5 siswa tidak terdapat perbedaan secara signifikan antara siswa yang mendapatkan pembelajaran WO dengan siswa yang mendapatkan pembelajaran TP. Dari hasil tersebut dapat disimpulkan bahwa secara keseluruhan pembelajaran strategi pemecahan masalah WankatOreovocz (WO) dan pembelajaran dengan Teknik Probing berpengaruh terhadap kemampuan literasi matematis level 5 siswa.

Hasil tersebut memberikan gambaran bahwa pembelajaran WO dan TP dapat mengembangkan literasi matematis level 5 siswa pada level 5 . Hal ini terjadi karena dalam pembelajaran WO memberikan kesempatan yang luas kepada siswa untuk menyelesaikan masalah yang diberikan dengan langkah-langkah dan strategi mereka sendiri, pembelajaran ini melatih siswa secara intensif dalam menyelesaikan suatu permasalahan, yang pada akhirnya siswa akan dapat merumuskan, menggunakan, dan menginterpretasi berdasarkan data-data yang diberikan sebelumnya sehingga siswa akan meningkat kemampuan berpikir matematisnya khususnya ke literasi matematis level 5 siswa. Di samping itu pemberian motivasi terhadap manfaat dari setiap penyelesaian masalah yan diselesaikan membantu memunculkan rasa percaya diri dalam diri siswa terhadap pelajaran matematika sehingga pelaksanaan strategi pemecahan masalah berjalan sesuai yang diharapkan. 
Selanjutnya, pembelajaran $\mathrm{TP}$ juga sangat mendukung untuk meningkatkan literasi matematis level 5 siswa sebab pada pembelajarannya siswa dituntut untuk dapat menyelesaikan masalah baru. Masalah tersebut diselesaikan dengan cara memberikan serangkaian pertanyaan kepada siswa sehingga seluruh siswa berpikir untuk dapat menyelesaikan masalah. Seri pertanyaan yang diberikan merupakan pertanyaan dari tingkat sederhana ke tingkat yang lebih tinggi sehingga dengan pertanyaanpertanyaan tersebut menuntun siswa dalam menyelesaikan masalah, pertanyaan yang diajukan sangat berpengaruh terhadap perkembangan keterampilan berpikir siswa. Pertanyaan-pertanyaan tersebut bukan hanya untuk memfokuskan siswa pada kegiatan, tetapi juga untuk menggali potensi belajar mereka. Pertanyaan akan memicu siswa untuk berpikir analitis dan dapat melatih siswa untuk menjadi pemikir yang kritis dan kreatif. Kondisi di atas akan terjadi apabila pertanyaan disusun sedemikian rupa sehingga dapat meningkatkan keterampilan berpikir siswa khususnya literasi matematis level 5 siswa.

\section{KESIMPULAN DAN SARAN}

Berdasarkan hasil penelitian dan pembahasan terhadap hasil-hasil penelitian sebagaimana yang diuraikan mengenai perbedaan kemampuan literasi matematis level 5 antara siswa yang mendapatkan pembelajaran dengan strategi pemecahan masalah Wankat-Oreovocz (WO) dan siswa yang mendapatkan pembelajaran dengan Teknik Probing (TP) maka diperoleh kesimpulan bahwa tidak terdapat perbedaan kemampuan literasi matematis level 5 pada siswa yang mendapat pembelajaran strategi pemecahan masalah Wankat-Oreovocz (WO) dan siswa yang mendapat pembelajaran Teknik Probing (TP).

Berdasarkan kesimpulan penelitian di atas, diajukan beberapa saran sebagai berikut: (1) Pembelajaran dengan strategi pemecahan masalah Wankat-Oreovocz (WO) dan pembelajaran dengan Teknik Probing (TP) hendaknya menjadi alternatif pembelajaran sebagai implementasi dari pengembangan pembelajaran matematika khususnya dalam meningkatkan literasi matematis level 5; (2) Pada penelitian ini dilakukan pada level sekolah sedang, sehingga perlu dilakukan penelitian lanjutan pada level sekolah tinggi atau rendah untuk mengetahui bagaimana pengaruh pembelajaran dengan strategi pemecahan masalah Wankat-Oreovocz (WO) dan pembelajaran dengan Teknik Probing (TP) terhadap literasi matematis level 5 . 


\section{DAFTAR PUSTAKA}

Balitbang. (2011). Laporan Hasil TIMSS 2007. Kementerian Pendidikan dan Kebudayaan.

Depdiknas. (2006). Kurikulum 2006 Mata Pelajaran Matematika SMP/MTs. Jakarta: Departemen Pendidikan Nasional. [13 Desember 2012].

Maryanti, E. (2012). Peningkatan Literasi Matematis Siswa Melalui Pendekatan Metacognitive Guidance. Tesis pada SPs Universitas Pendidikan Indonesia. Bandung: tidak diterbitkan..

OECD. (2010). Draft PISA 2012 Assesment Framework. [online]. Tersedia di: http://www.oecd.org/dataoecd/6 1/15/46241909.pdf. diakses 13 Oktober 2012.

Ruseffendi, E.T. (2005). Dasar-Dasar Penelitian Pendidikan dan Bidang Non-Eksakta Lainnya. Bandung: Tarsito

Wena, M. (2009). Strategi Pembelajaran Inovatif Kontemporer Suatu Tinjauan Operasional. Jakarta: Bumi Aksara. 